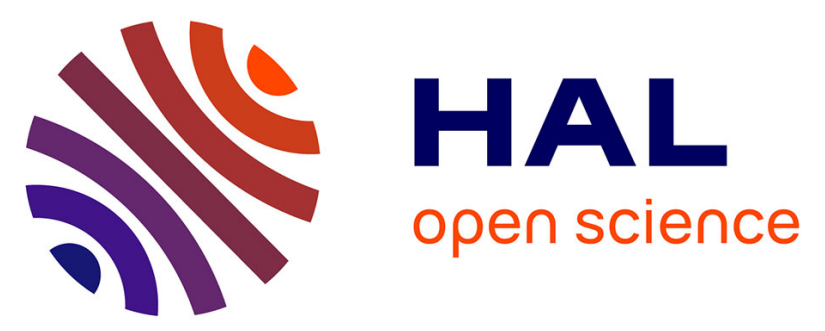

\title{
Diversity among strains of Pseudomonas aeruginosa from manure and soil, evaluated by multiple locus variable number tandem repeat analysis and antibiotic resistance profiles
}

Benjamin Youenou, Elisabeth Brothier, Sylvie Nazaret

\section{To cite this version:}

Benjamin Youenou, Elisabeth Brothier, Sylvie Nazaret. Diversity among strains of Pseudomonas aeruginosa from manure and soil, evaluated by multiple locus variable number tandem repeat analysis and antibiotic resistance profiles. Research in Microbiology, 2014, 10.1016/j.resmic.2013.10.004 . hal02335599

\section{HAL Id: hal-02335599 \\ https://hal.science/hal-02335599}

Submitted on 29 Oct 2019

HAL is a multi-disciplinary open access archive for the deposit and dissemination of scientific research documents, whether they are published or not. The documents may come from teaching and research institutions in France or abroad, or from public or private research centers.
L'archive ouverte pluridisciplinaire HAL, est destinée au dépôt et à la diffusion de documents scientifiques de niveau recherche, publiés ou non, émanant des établissements d'enseignement et de recherche français ou étrangers, des laboratoires publics ou privés. 


\title{
Diversity among strains of Pseudomonas aeruginosa from manure and soil, evaluated by multiple locus variable number tandem repeat analysis and antibiotic resistance profiles
}

\author{
Benjamin Youenou*, Elisabeth Brothier, Sylvie Nazaret
}

Université de Lyon, Research Group on "Environmental Multiresistance and Efflux Pumps", CNRS, Ecole nationale vétérinaire de Lyon, and Université Lyon 1, UMR 5557 Ecologie microbienne, 43 Boulevard du 11 Novembre 1918, 69622 Villeurbanne cedex, France

Received 5 June 2013; accepted 3 September 2013

Available online 17 October 2013

\begin{abstract}
The results of a multiple locus variable number of tandem repeat (VNTR) analysis (MLVA)-based study designed to understand the genetic diversity of soil and manure-borne Pseudomonas aeruginosa isolates, and the relationship between these isolates and a set of clinical and environmental isolates, are hereby reported. Fifteen described VNTR markers were first selected, and 62 isolates recovered from agricultural and industrial soils in France and Burkina Faso, and from cattle and horse manure, along with 26 snake-related isolates and 17 environmental and clinical isolates from international collections, were genotyped. Following a comparison with previously published 9-marker MLVA schemes, an optimal 13-marker MLVA scheme (MLVA 13 -Lyon) was identified that was found to be the most efficient, as it showed high typability (90\%) and high discriminatory power (0.987). A comparison of MLVA with PFGE for typing of the snake-related isolates confirmed the MLVA 13 -Lyon scheme to be a robust method for quickly discriminating and inferring genetic relatedness among environmental isolates. The 62 isolates displayed wide diversity, since 41 MLVA types (i.e. MTs) were observed, with 26 MTs clustered in 10 MLVA clonal complexes (MCs). Three and eight MCs were found among soil and manure isolates, respectively. Only one MC contained both soil and manure-borne isolates. No common MC was observed between soil and manure-borne isolates and the snake-related or environmental and clinical isolates. Antibiotic resistance profiles were performed to determine a potential link between resistance properties and the selective pressure that might be present in the various habitats. Except for four soil and manure isolates resistant to ticarcillin and ticarcillin/clavulanic acid and one isolate from a hydrocarbon-contaminated soil resistant to imipenem, all environmental isolates showed wild-type antibiotic profiles.
\end{abstract}

(C) 2013 Institut Pasteur. Published by Elsevier Masson SAS. All rights reserved.

Keywords: Pseudomonas aeruginosa; Antibiotics; Resistance; MLVA typing

\section{Introduction}

Pseudomonas aeruginosa, a ubiquitous Gram-negative bacterium, is known to be an opportunistic human pathogen and an important cause of infection in immunocompromised patients. It is responsible for severe nosocomial pneumonias among intensive care unit patients and for the chronic lung infections of patients with cystic fibrosis [26,27]. Community-

\footnotetext{
* Corresponding author.

E-mail addresses: benjamin.youenou@gmail.com (B. Youenou), sylvie. nazaret@univ-lyon1.fr (S. Nazaret).
}

acquired infections in healthy individuals have also been reported, including keratitis [41], otitis [15] and dermatitis [44]. In addition, $P$. aeruginosa causes a wide variety of diseases in animals, such as ocular infections in dogs [25] and cattle mastitis [8]. This species is characterized by inherent resistance to numerous antimicrobial agents due to its low membrane permeability and the presence of several drug efflux systems and porins, as well as a remarkable ability to acquire further resistance mechanisms.

$P$. aeruginosa is a metabolically versatile bacterium capable of surviving in natural and human-associated environments. It has been frequently isolated from a wide range of aquatic 
environments including rivers [32], sea water [22], swimming pools [3], bottled water [17] and wastewater [11]. It has also been recovered from terrestrial environments such as agricultural soils [12] and hydrocarbon-polluted sites [10], but at a lower frequency [37].

Studies on the genetic structure of $P$. aeruginosa populations have been massively conducted on clinical isolates for ecological and epidemiological purposes $[7,23,50]$ using various molecular typing methods. Pulsed field gel electrophoresis (PFGE), the "gold standard" method, showed high discriminatory power in epidemiology studies [13]. However, this technique does not allow easy comparison of results between different studies because of interlaboratory variations in the reproducibility and absence of an international database [46]. Multi-Locus sequence typing (MLST) is an increasingly used technique, but it remains expensive and is less discriminatory than PFGE for detecting genetic differences among related $P$. aeruginosa isolates [18]. In recent years, multiple locus VNTR analysis (MLVA), a PCR-based typing method in which isolates are characterized by the number of repeat units at each locus [47], has been developed and optimized, leading to several schemes validated in studies on $P$. aeruginosa clinical isolates [39,45,46,48]. Recently, [39] developed a high-throughput MLVA assay based on multiplex PCRs, followed by capillary electrophoresis to evaluate strain evolution during long-term colonization of cystic fibrosis patients. MLVA-based studies showed that this approach is highly discriminatory and reproducible, congruent with PFGE analysis, easy to standardize and applicable to a large number of samples at a low cost. Nevertheless, all these molecular typing methods have been primarily developed and used for surveillance of epidemic strains and for investigation into the global population structure of $P$. aeruginosa. Studies using these typing methods focused on clinical isolates and compared them to isolates mainly from aquatic environments but rarely from terrestrial ones. Furthermore, MLVA protocols have not yet been tested to type and infer genetic relatedness among environmental isolates or between environmental and clinical isolates.

The aim of this study was to understand the genetic diversity of soil- and manure-borne $P$. aeruginosa isolates and the relationship between these isolates and a set of clinical and other soil-related isolates mostly selected from international collections. For these purposes, an MLVA assay was used. Our strategy first relied on the selection of a set of 15 VNTR loci made of all the loci used in the MLVA $_{9}$-London [45] and MLVA $_{9}$-Utrecht [46] schemes, in order to evaluate whether one of these simplified schemes would be robust enough for genotyping of our soil-related isolates. This preliminary step enabled development of the $\mathrm{MLVA}_{13}$-Lyon scheme, whose discriminatory efficiency was compared to that of PFGE typing using a subset of 26 previously studied snake-related isolates [5]. This typing scheme was then applied to isolates recovered either from agricultural and industrial soils or from horse and cattle manure sampled in various areas in France and Burkina Faso. As P. aeruginosa strains from manure can originate from animals exposed to antibiotics that might exert a selective pressure on resistance emergence, the antibiotic susceptibilities of these strains were also evaluated.

\section{Materials and methods}

\subsection{Bacterial isolates and DNA preparation}

A set of 105 isolates was used in the present study (Table 1). Seventeen were from public international collections and were isolated from clinical $(n=7)$ and environmental $(n=10)$ sources. Among them, strains PAO1 and PA14 were included to be used as standards in each MLVA electrophoresis assay. Eighty-eight environmental isolates were from our laboratory collection (available from the EML Biological Resource Center at http:// www.eml-brc.org/). They had been isolated on Cetrimide agar base medium supplemented with nalidixic acid from samples of various origins harvested between 2005 and 2011. Isolation and identification procedures were as described previously [6]. Twenty-three isolates were of soil origin: 12 were isolated from industrial sites contaminated with hydrocarbons (Neuves-Maisons in the Lorraine region and Paris in the Ile-de-France region, France), three from a vineyard field amended with mushroom manure (i.e. a compost of horse manure and straw that is used to grow mushrooms; Chinon, in the Burgundy region, France) and eight from a field planted with sorghum and amended with raw urban waste in the periphery of Ouagadougou in Burkina Faso. Thirty-nine isolates were from manure samples: 11 from horse manure collected from two sites in the Rhône-Alpes region (six from the National Veterinary School of Lyon, Marcy l'Etoile and five from a farm in Saint Olive), 13 from cattle manure collected at two farms in Feucherolles, Ile-de-France $(n=8)$ and Versailleux, Rhône-Alpes $(n=5)$ and 15 from composted horse manure supplemented with either crude farm wheat straw (farm 1) or commercial wheat straw (Hippogold $囚$ ) (farm 2) in Versailles (Ilede-France). There were also 26 strains isolated from snake breeding facilities (healthy snake feces, cages, feeding samples), which had been previously characterized by PFGE SpeI profiles [5].

Isolates were grown at $28{ }^{\circ} \mathrm{C}$ in Luria-Bertani broth under agitation $(160 \mathrm{rpm})$. Twenty $\mathrm{ml}$ of an overnight culture were used for DNA extraction. Extraction was carried out as previously described [34]. The DNA concentration was estimated with an ND-1000 spectrophotometer (NanoDrop; Labtech, Palaiseau, France).

\subsection{MLVA genotyping}

A set of 15 VNTR loci was selected for this study (Table 2). It included 12 minisatellites (ms77, ms127, ms142, ms172, ms211, ms213, ms214, ms215, ms216, ms217, ms222, ms223) and three microsatellites (ms61, ms207, ms209) previously described in [29] and [48].

To lower the number of PCR reactions, multiplex PCR was developed for nine of the 15 selected loci (multiplex 1: ms209, ms77, ms 172; multiplex 2: ms214, ms61; multiplex 3: ms207, ms216; multiplex 4: ms127, ms222). Other loci were classically amplified in single PCR reactions. Single and multiplex 
Table 1

List of strains and isolates, with their origin, sampling location, year of isolation and previously published labels.

\begin{tabular}{|c|c|c|c|c|}
\hline Name & Origin & Location & Isolation year & Previous labels (respectively) \\
\hline \multicolumn{5}{|l|}{ Reference strains } \\
\hline PAO1 & Wound, clinical & Melbourne (Australia) & 1955 & \\
\hline PA14 & Burn, clinical & $\begin{array}{l}\text { UCBPP collection, Berkeley } \\
\text { California, (USA) }\end{array}$ & & \\
\hline PA5 & Intensive Care Unit, clinical & Brussels (Belgium) & & \\
\hline PA6 & Urinary tract infection, clinical & Brussels (Belgium) & & \\
\hline PA12 & Urinary tract infection, clinical & Brussels (Belgium) & & \\
\hline ATCC 15691 & Urinary tract infection, clinical & Cape Town (South Africa) & 1950 & \\
\hline ATCC 27853 & Blood, clinical & Boston (USA) & 1971 & \\
\hline ATCC 21776 & Soil & Chiba (Japan) & 1974 & \\
\hline ATCC 31479 & Soil & Salem, Virginia (USA) & 1981 & \\
\hline CIP 104590 & PAH-contaminated soil & Munich (Germany) & 1995 & \\
\hline LMD 50.34 & Soil & Bogor (Indonesia) & 1949 & \\
\hline LMD 68.7 & Garden soil & Delft (Netherlands) & 1968 & \\
\hline LMG 15153 & Permian salt deposits & Nauheim (Germany) & 1963 & \\
\hline 7NSK2 & Barley roots & Melle (Belgium) & 1983 & \\
\hline CFBP 5036 & Oil-contaminated soil & USA & 1987 & \\
\hline CFBP 5037 & Oil-contaminated soil & USA & 1987 & \\
\hline ATCC 33988 & Fuel storage tank & $\begin{array}{l}\text { Ponca City, Oklahoma, } \\
\text { (USA) }\end{array}$ & & \\
\hline \multicolumn{5}{|l|}{ Team strain collection } \\
\hline \multicolumn{5}{|l|}{ Soil } \\
\hline $\begin{array}{l}\text { EML1316, EML1317, EML1319, EML1320, } \\
\text { EML1321, EML1322, EML1323, } \\
\text { EML1324, EML1325 }\end{array}$ & Hydrocarbon- impacted soil & $\begin{array}{l}\text { Neuves Maisons, } \\
\text { Lorraine (France) }\end{array}$ & 2005 & $\begin{array}{l}\text { bpoe1428, bpoe1429, bpoe1431, bpoe1432, } \\
\text { bpoe1433, bpoe1444, bpoe1445, } \\
\text { bpoe1447, bpoe1454 }\end{array}$ \\
\hline EML1331, EML1332, EML1333 & Hydrocarbon- impacted soil & Paris, Île de France (France) & 2005 & bpoe1464, bpoe1465, bpoe1466 \\
\hline EML1326, EML1327, EML1328 & $\begin{array}{l}\text { Vineyard soil amended with } \\
\text { mushroom manure }\end{array}$ & Chinon, Burgundy (France) & 2005 & bpoe1457, bpoe1459, bpoe1460 \\
\hline $\begin{array}{l}\text { EML1257, EML1258, EML1259*, EML1260*, } \\
\text { EML1261*, EML1262*, EML1263*, EML1264* }\end{array}$ & $\begin{array}{l}\text { Raw urban waste- } \\
\text { contaminated soil }\end{array}$ & Tabtenga (Burkina Faso) & $\begin{array}{l}2007 \\
\text { (EML1257) } \\
2011\end{array}$ & \\
\hline \multicolumn{5}{|l|}{ Manure } \\
\hline $\begin{array}{l}\text { EML1318, EML1329, EML1330, } \\
\text { EML1334, EML1335, EML1336 }\end{array}$ & Horse manure & $\begin{array}{l}\text { Marcy l'Etoile, } \\
\text { Rhône-Alpes (France) }\end{array}$ & 2004 & $\begin{array}{l}\text { bpoe1430, bpoe1461, bpoe1462, } \\
\text { bpoe1474, bpoe1475, bpoe1479 }\end{array}$ \\
\hline $\begin{array}{l}\text { EML1270, EML1271, EML1272, } \\
\text { EML1273, EML1274 }\end{array}$ & Horse manure & $\begin{array}{l}\text { Saint Olive, } \\
\text { Rhône-Alpes (France) }\end{array}$ & 2012 & \\
\hline $\begin{array}{l}\text { EML1275, EML1276, EML1277, } \\
\text { EML1278, EML1279, } \\
\text { EML1280, EML1281, EML1282 }\end{array}$ & Cattle manure & $\begin{array}{l}\text { Feucherolles, Île- } \\
\text { de-France (France) }\end{array}$ & 2006 & \\
\hline $\begin{array}{l}\text { EML1265, EML1266, EML1267, } \\
\text { EML1268, EML1269 }\end{array}$ & Cattle manure & $\begin{array}{l}\text { Versailleux, } \\
\text { Rhône-Alpes (France) }\end{array}$ & 2012 & \\
\hline $\begin{array}{l}\text { EML1283, EML1284, EML1285, } \\
\text { EML1292, EML1293, } \\
\text { EML1294, EML1295, EML1296, EML1297 }\end{array}$ & $\begin{array}{l}\text { Compost of farm straw } \\
\text { and horse manure }\end{array}$ & $\begin{array}{l}\text { Farm } 1 \text { Versailles, } \\
\text { Île-de- France (France) }\end{array}$ & 2011 & \\
\hline $\begin{array}{l}\text { EML1286, EML1287, EML1288, } \\
\text { EML1289, EML1290, EML1291 }\end{array}$ & $\begin{array}{l}\text { Compost of commercial } \\
\text { straw (Hippogold }{ }^{\circledR} \text { ) } \\
\text { and horse manure }\end{array}$ & $\begin{array}{l}\text { Farm } 2 \text { Versailles, } \\
\text { Île-de- France (France) }\end{array}$ & 2011 & \\
\hline
\end{tabular}




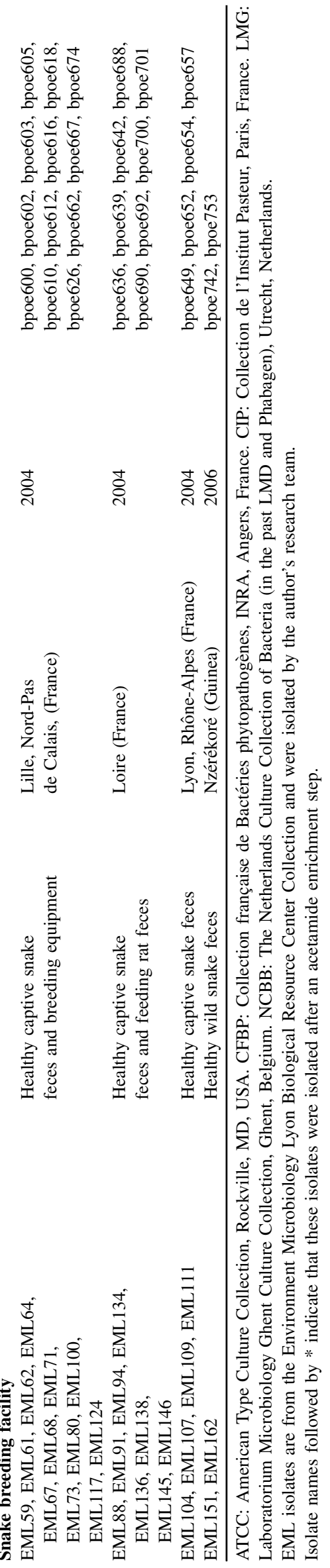

PCRs were performed in $25 \mu$ volumes containing 20-40 ng of DNA template, $1 \times$ PCR buffer, $200 \mu \mathrm{M}$ of each dNTP, $0.5 \mu \mathrm{M}$ of each primer, $1 \mathrm{U}$ of Taq polymerase (MP Biomedical, Illkirch, France) and DMSO at a final concentration of $5 \% \mathrm{w} / \mathrm{vol}$. Forward primers were differentially labeled with IRDye 700 and IRDye 800 to distinguish the PCR products after migration on acrylamide gels. Amplifications were performed in a PTC 200 thermocycler (MJ-Research, Marnes-la-Coquette, France) under the following conditions: an initial denaturation cycle for $5 \mathrm{~min}$ at $95^{\circ} \mathrm{C}$ and 35 cycles of denaturation for $30 \mathrm{~s}$ at $95^{\circ} \mathrm{C}$, annealing for $30 \mathrm{~s}$ at $58^{\circ} \mathrm{C}$ and elongation for $45 \mathrm{~s}$ at $72{ }^{\circ} \mathrm{C}$ followed by a final elongation step for $8 \mathrm{~min}$ at $72{ }^{\circ} \mathrm{C}$.

Separation of the PCR products was performed in a LI$\mathrm{COR}^{\circledR} 4300$ DNA analyzer (ScienceTec, Les Ulis, France) with $5.5 \% \mathrm{w} / \mathrm{vol}$ acrylamide gels under the following conditions: a pre-run of $25 \mathrm{~min}$ at $2000 \mathrm{~V}, 40 \mathrm{~W}, 45^{\circ} \mathrm{C}$ and a run of $2 \mathrm{~h} 30$ at $2000 \mathrm{~V}, 40 \mathrm{~W}, 45^{\circ} \mathrm{C}$. To minimize the number of wells needed for the migration, PCR products were pooled in five different combinations (Table 2). The following five pools were then diluted 50- to 100-fold to reduce the amount of fluorescence and to avoid saturation of the sensor. According to the manufacturer's recommendations, after the first migration run, the gels were reloaded for a second run without a pre-run step.

\subsection{Data analysis}

Gel data were collected and the different allele sizes were determined with $\mathrm{SAGA}^{\mathrm{GT}}$ software (ScienceTec). The different genotypes of the samples were constructed by expressing the number of repeats for each locus according to the PAO1 sequence as a reference and by using the chart of the different allele sizes observed by [48] proposed on the website http://bacterial-genotyping.igmors.u-psud.fr/pseudomonas/.

When the allele size measured for an amplicon was not previously described, an allele number was attributed if the size of the amplicon matched a hypothetical number of copies for the locus. As previously described, intermediate-sized alleles resulting from intermediate-sized repeat units or small deletions in the sequence were reported as half sizes. Alleles of unexpected size with non-attributable allele number and loci that did not yield PCR products over 3 PCR reactions were assigned allele "99" to ascribe these isolates for further clustering analysis. These alleles of unexpected sizes or nonamplifiable alleles can be produced by insertion of IS elements as described in [48], but this was not confirmed.

Typability criteria defined by [28] were calculated as described in [46] as the number of isolates for which repeat number could be inferred for all loci of the MLVA set divided by all isolates tested.

The discriminatory indices (DIs) of each VNTR locus and MLVA typing scheme were calculated by use of the HunterGaston Discriminatory Index (HGDI) [16], an application of Simpson's index of diversity [38]. The 95\% confidence intervals (CI) were calculated as described in [14].

MTs obtained with the different MLVA typing schemes were clustered with the $\mathrm{R}$ software using a categorical 


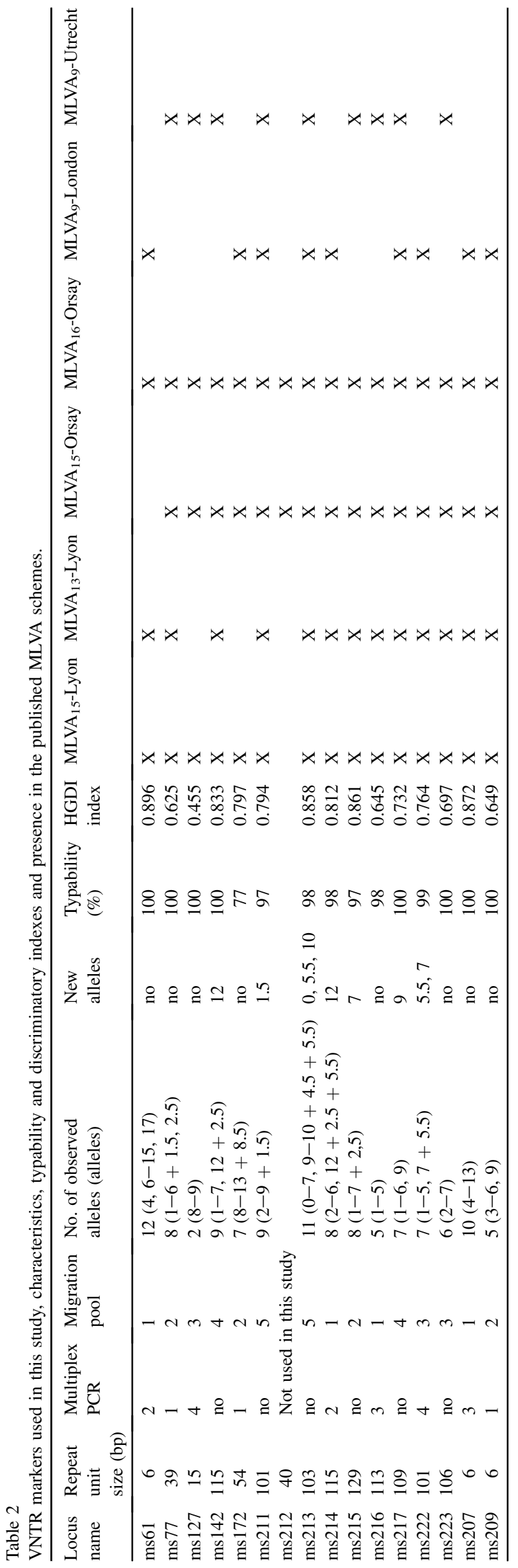

coefficient (also called Hamming's distance) and the unweighted pair group method with arithmetic mean (UPGMA) clustering method [40]. An MLVA type (MT) is a genotype obtained by MLVA typing. An MLVA clonal complex (MC) is defined as the clustering of MTs that differs at a maximum of two VNTRs, which corresponds to an interval of $85-100 \%$ similarity between MTs.

The quantitative level of congruence between the typing schemes was calculated using adjusted [35] and [49] coefficients available at http://www.comparingpartitions.info/. The adjusted Rand coefficient defines the global agreement between two methods or two protocols, whereas the adjusted Wallace coefficient indicates the probability that two isolates classified as the same type following a given protocol are also classified as the same type using another protocol [4].

\subsection{Antibiotic resistance test}

The in vitro antimicrobial resistance patterns of $P$. aeruginos $a$ were determined using the Vitek ${ }^{\circledR} 2$ system with a card (NO93) dedicated to non-fermenting Gram-negative bacteria (Biomérieux, Marcy l'Etoile, France) according to the manufacturer's instructions. P. aeruginosa ATCC 27853 (wild-type) was used as a control strain. Minimum inhibitory concentration (MIC) results were analyzed using the $\mathrm{AES}^{\mathrm{TM}}$ (Advanced Expert System) software incorporated in this system. Snakerelated isolates and part of our set of soil and manure isolates were previously tested in [5] and [9], respectively.

\section{Results}

\subsection{MLVA schemes: efficiency and comparison}

The MLVA typing method has not yet been used on environmental isolates. An MLVA scheme $\left(\mathrm{MLVA}_{15}\right.$-Lyon) made up of a set of 15 VNTRs previously used in the two published and simplified MLVA $_{9}$-London and MLVA $_{9}$-Utrecht MLVA schemes (Table 2) was first tested. The rationale behind this strategy was to evaluate whether one of these simplified schemes or a new scheme combining the lowest number of VNTRs would enable efficient discrimination and clustering of soil-related isolates.

The 15 VNTR markers selected for MLVA $_{15}$-Lyon showed typability superior to $97 \%$ except for the ms 172 marker (Table 2 ), where an absence of amplification was frequently observed when typing manure isolates from miscellaneous sampling sites (Table 3). This lack of amplification can be explained by mismatches in the primer target regions (Fig. 1) or by rearrangements in the genomic sequence of the locus (large insertion sequences, partial or complete deletion of the VNTR flanking sequence) but this was not confirmed.

The HGDI of each marker considered separately was superior to 0.625 except for the ms 127 marker, that showed an HGDI of 0.455 . Alleles not previously described in the literature were observed for VNTRs ms142, ms211, ms213, ms214, ms215, ms217 and ms222 (Table 2). These new alleles occurred among isolates from both soil and manure. 
Table 3

Number of repeats for each marker, MLVA type (MT) and MLVA clonal complex (MC) for the studied P. aeruginosa isolates.

\begin{tabular}{|c|c|c|c|c|c|c|c|c|c|c|c|c|c|c|c|c|c|}
\hline \multirow[t]{2}{*}{ Sample } & \multirow[t]{2}{*}{ MT MLVA $_{13}$-Lyon } & \multirow[t]{2}{*}{$\mathrm{MC}$} & \multicolumn{15}{|c|}{ VNTR } \\
\hline & & & 61 & 207 & 209 & 77 & 127 & 142 & 172 & 211 & 213 & 214 & 215 & 216 & 217 & 222 & 223 \\
\hline PAO1 & 1 & & 12 & 7 & 6 & 4 & 8 & 7 & 12 & 5 & 5 & 3 & 4 & 3 & 2 & 2 & 4 \\
\hline PA14 & 2 & & 12 & 5 & 6 & 2 & 9 & 1 & 12 & 2 & 1 & 5 & 2 & 1 & 5 & 2 & 4 \\
\hline PA5 & 3 & & 8 & 12 & 6 & 4 & 9 & 2 & 12 & 2 & 5 & 3 & 2 & 1 & 2 & 2 & 2 \\
\hline PA6 & 4 & & 8 & 6 & 5 & 2.5 & 8 & 4 & 11 & 3 & 4.5 & 3 & 2 & 2 & 2 & 2 & 2 \\
\hline PA12 & 5 & & 8 & 11 & 5 & 2 & 8 & 12 & 99 & 5 & 2 & 5.5 & 5 & 3 & 9 & 3 & 3 \\
\hline ATCC 15691 & 6 & & 9 & 7 & 5 & 2.5 & 8 & 4 & 11 & 2 & 3 & 4 & 5 & 1 & 3 & 3 & 7 \\
\hline ATCC 27853 & 7 & & 9 & 9 & 5 & 2.5 & 8 & 5 & 11 & 4 & 5 & 2 & 4 & 2 & 3 & 2 & 2 \\
\hline ATCC 21776 & 8 & & 8 & 5 & 4 & 2.5 & 8 & 4 & 8 & 7 & 4 & 5 & 6 & 2 & 3 & 3 & 2 \\
\hline ATCC 31479 & 9 & & 11 & 7 & 3 & 4 & 9 & 1 & 10 & 2 & 4 & 2 & 2 & 1 & 4 & 3 & 2 \\
\hline CIP 104590 & 10 & & 9 & 4 & 4 & 2.5 & 8 & 2.5 & 8.5 & 8 & 5 & 2 & 1 & 2 & 1 & 2 & 2 \\
\hline LMD 50.34 & 11 & & 8 & 10 & 4 & 2.5 & 8 & 1 & 13 & 3 & 4 & 5 & 1 & 1 & 2 & 1 & 2 \\
\hline LMD 68.7 & 12 & & 14 & 9 & 3 & 2.5 & 8 & 3 & 11 & 6 & 5 & 4 & 2 & 2 & 3 & 3 & 2 \\
\hline LMG 15153 & 13 & & 13 & 6 & 3 & 2.5 & 8 & 3 & 12 & 3 & 3 & 5 & 5 & 2 & 1 & 4 & 4 \\
\hline 7NSK2 & 14 & & 8 & 5 & 4 & 2.5 & 8 & 4 & 12 & 3 & 4 & 2 & 6 & 2 & 2 & 1 & 5 \\
\hline CFBP 5036, CFBP5037 & 15 & & 13 & 10 & 3 & 2.5 & 9 & 1 & 12 & 3 & 4.5 & 5.5 & 4 & 3 & 4 & 3 & 4 \\
\hline ATCC 33988 & 16 & & 10 & 7 & 3 & 2.5 & 8 & 4 & 11 & 2 & 4.5 & 5 & 5 & 2 & 2 & 2 & 5 \\
\hline EML59 & 17 & & 10 & 9 & 3 & 4 & 9 & 12 & 10 & 2 & 1 & 2 & 2 & 1 & 1 & 1 & 3 \\
\hline $\begin{array}{l}\text { EML61, EML62, EML68, } \\
\text { EML124, EML136 }\end{array}$ & 18 & 2 & 10 & 4 & 4 & 2.5 & 8 & 3 & 8.5 & 8 & 5 & 2 & 1 & 2 & 1 & 2 & 3 \\
\hline EML64, EML100 & 19 & 16 & 7 & 7 & 4 & 2.5 & 9 & 7 & 11 & 2 & 4 & 5 & 5 & 2 & 2 & 2 & 5 \\
\hline EML67, EML117 & 20 & 5 & 7 & 8 & 4 & 6 & 9 & 1 & 10 & 2 & 1 & 2.5 & 2 & 1 & 4 & 4 & 3 \\
\hline EML71 & 21 & 5 & 7 & 8 & 4 & 6 & 9 & 1 & 10 & 2 & 1 & 4 & 2 & 1 & 4 & 4 & 3 \\
\hline EML73 & 22 & 5 & 7 & 9 & 4 & 6 & 9 & 1 & 10 & 2 & 1 & 2.5 & 2 & 1 & 4 & 4 & 3 \\
\hline EML80 & 23 & & 15 & 8 & 4 & 6 & 9 & 1 & 10 & 2 & 4 & 3 & 1 & 2 & 3 & 3 & 2 \\
\hline EML88, EML134, EML146 & 24 & 15 & 14 & 11 & 3 & 2.5 & 8 & 5 & 12 & 2 & 1 & 5 & 4 & 1 & 2 & 2 & 5 \\
\hline EML91 & 25 & 7 & 14 & 6 & 3 & 2.5 & 9 & 1 & 12 & 5 & 6 & 2 & 2 & 1 & 4 & 1 & 2 \\
\hline EML94 & 26 & & 8 & 5 & 6 & 2.5 & 8 & 6 & 10 & 3 & 5 & 4 & 6 & 2 & 4 & 4 & 2 \\
\hline EML104 & 27 & & 10 & 8 & 5 & 2.5 & 8 & 5 & 11 & 2 & 3 & 5 & 6 & 1 & 2 & 2 & 2 \\
\hline EML107, EML111 & 28 & 8 & 12 & 7 & 4 & 2 & 9 & 1 & 12 & 2 & 5 & 3 & 1 & 2 & 2 & 3 & 6 \\
\hline EML109 & 29 & 16 & 4 & 7 & 4 & 2.5 & 8 & 7 & 11 & 2 & 0 & 5 & 5 & 2 & 2 & 2 & 5 \\
\hline EML138 & 30 & 7 & 9 & 6 & 3 & 2.5 & 9 & 1 & 12 & 5 & 6 & 99 & 2 & 1 & 4 & 1 & 2 \\
\hline EML145 & 31 & 7 & 15 & 6 & 3 & 2.5 & 9 & 1 & 12 & 5 & 6 & 2 & 2 & 1 & 4 & 1 & 2 \\
\hline EML151, EML162 & 32 & 4 & 6 & 9 & 4 & 2.5 & 9 & 1 & 10 & 3 & 5 & 12 & 1 & 1 & 4 & 4 & 4 \\
\hline EML1257 & 33 & & 7 & 11 & 3 & 2.5 & 8 & 12 & 11 & 99 & 3 & 4 & 99 & 3 & 4 & 1 & 2 \\
\hline EML1258 & 34 & & 6 & 9 & 3 & 1 & 8 & 6 & 99 & 4 & 1 & 5 & 3 & 3 & 6 & 1 & 5 \\
\hline EML1259 & 35 & & 12 & 10 & 4 & 3 & 8 & 5 & 13 & 3 & 4 & 5 & 1 & 1 & 3 & 1 & 3 \\
\hline EML1260 & 36 & & 12 & 6 & 3 & 2.5 & 8 & 5 & 8 & 3 & 4 & 5 & 4 & 2 & 2 & 3 & 2 \\
\hline EML1261 & 37 & & 6 & 4 & 4 & 2.5 & 9 & 5 & 12 & 6 & 1 & 3 & 6 & 2 & 4 & 4 & 4 \\
\hline EML1262 & 38 & & 7 & 4 & 4 & 2.5 & 8 & 2 & 10 & 7 & 5 & 5 & 5 & 3 & 2 & 3 & 2 \\
\hline EML1263 & 39 & & 9 & 8 & 3 & 2.5 & 8 & 6 & 11 & 4 & 99 & 5 & 4 & 2 & 4 & 3 & 2 \\
\hline EML1264 & 40 & & 9 & 4 & 3 & 2 & 8 & 2 & 11 & 3 & 4 & 5 & 2 & 2 & 2 & 1 & 3 \\
\hline EML1265 & 41 & 6 & 14 & 10 & 6 & 2.5 & 9 & 1 & 12 & 1.5 & 5 & 2 & 1 & 99 & 5 & 2 & 2 \\
\hline EML1266 & 42 & 14 & 14 & 9 & 6 & 2.5 & 8 & 5 & 12 & 3 & 5 & 5 & 4 & 2 & 2 & 5 & 2 \\
\hline EML1267 & 43 & 14 & 10 & 9 & 6 & 2.5 & 8 & 5 & 12 & 3 & 5 & 5 & 4 & 2 & 2 & 5 & 2 \\
\hline EML1268 & 44 & & 10 & 12 & 3 & 2 & 8 & 6 & 99 & 4 & 5.5 & 5.5 & 6 & 2 & 2 & 7 & 3 \\
\hline EML1269 & 45 & 6 & 12 & 10 & 6 & 2.5 & 9 & 1 & 12 & 1.5 & 5 & 2 & 1 & 99 & 5 & 2 & 2 \\
\hline EML1270 & 46 & & 8 & 10 & 3 & 2.5 & 9 & 1 & 99 & 3 & 99 & 5 & 2.5 & 1 & 4 & 1 & 2 \\
\hline EML1271, EML1272, EML1273 & 47 & 12 & 8 & 8 & 4 & 2.5 & 8 & 2 & 12 & 3 & 9 & 3 & 6 & 2 & 1 & 4 & 2 \\
\hline EML1274 & 48 & 12 & 12 & 8 & 4 & 2.5 & 8 & 2 & 12 & 3 & 9 & 3 & 6 & 2 & 1 & 4 & 2 \\
\hline EML1275, EML1283 & 49 & 3 & 13 & 6 & 4 & 1 & 8 & 5 & 99 & 5 & 10 & 4 & 5 & 2 & 1 & 3 & 4 \\
\hline EML1276 & 50 & & 15 & 6 & 5 & 2.5 & 8 & 4 & 8 & 3 & 5 & 5 & 3 & 4 & 3 & 1 & 2 \\
\hline EML1277, EML1282 & 51 & 1 & 9 & 10 & 4 & 3 & 8 & 5 & 99 & 99 & 7 & 5.5 & 7 & 5 & 2 & 2 & 3 \\
\hline EML1278 & 52 & & 11 & 11 & 5 & 2.5 & 8 & 4 & 11 & 8 & 3 & 3 & 5 & 3 & 2 & 3 & 5 \\
\hline EML1279, EML1281 & 53 & 1 & 9 & 10 & 4 & 3 & 8 & 5 & 99 & 9 & 7 & 5.5 & 7 & 5 & 2 & 2 & 3 \\
\hline EML1280 & 54 & & 17 & 10 & 4 & 2.5 & 9 & 1 & 10 & 4 & 5 & 99 & 5 & 1 & 2 & 99 & 5 \\
\hline EML1284 & 55 & 10 & 13 & 6 & 3 & 2.5 & 9 & 2 & 99 & 3 & 5 & 3 & 2.5 & 1 & 1 & 4 & 2 \\
\hline EML1285 & 56 & 10 & 7 & 6 & 3 & 2.5 & 9 & 2 & 99 & 3 & 5 & 3 & 2.5 & 1 & 1 & 4 & 2 \\
\hline $\begin{array}{l}\text { EML1286, EML1287, EML1288, } \\
\text { EML1289, EML1290, EML1291 }\end{array}$ & 49 & 3 & 13 & 6 & 4 & 1 & 8 & 5 & 99 & 5 & 10 & 4 & 5 & 2 & 1 & 3 & 4 \\
\hline EML1292 & 57 & 10 & 13 & 7 & 3 & 2.5 & 9 & 2 & 99 & 3 & 4 & 3 & 2.5 & 1 & 1 & 4 & 2 \\
\hline EML1293, EML1294, EML1295 & 58 & 10 & 7 & 7 & 3 & 2.5 & 9 & 2 & 99 & 3 & 4 & 3 & 2.5 & 1 & 1 & 4 & 2 \\
\hline
\end{tabular}


Table 3 (continued)

\begin{tabular}{|c|c|c|c|c|c|c|c|c|c|c|c|c|c|c|c|c|c|}
\hline \multirow[t]{2}{*}{ Sample } & \multirow[t]{2}{*}{ MT MLVA $_{13}$-Lyon } & \multirow[t]{2}{*}{$\mathrm{MC}$} & \multicolumn{15}{|c|}{ VNTR } \\
\hline & & & 61 & 207 & 209 & 77 & 127 & 142 & 172 & 211 & 213 & 214 & 215 & 216 & 217 & 222 & 223 \\
\hline EML1296 & 59 & 10 & 14 & 7 & 3 & 2.5 & 9 & 2 & 12 & 3 & 4 & 3 & 2.5 & 1 & 1 & 4 & 2 \\
\hline EML1297 & 60 & 10 & 7 & 7 & 3 & 2.5 & 9 & 2 & 99 & 3 & 4.5 & 3 & 2.5 & 1 & 1 & 4 & 2 \\
\hline $\begin{array}{l}\text { EML1316, EML1319, EML1320, } \\
\text { EML1321, EML1324, EML1325 }\end{array}$ & 61 & 9 & 11 & 11 & 3 & 2 & 8 & 1 & 12 & 2 & 1 & 2 & 2 & 1 & 2 & 3 & 4 \\
\hline EML1317 & 62 & 9 & 11 & 11 & 3 & 2 & 8 & 1 & 12 & 2 & 1 & 2 & 2 & 1 & 2 & 4 & 2 \\
\hline EML1318, EML1330 & 63 & 17 & 11 & 7 & 3 & 1.5 & 8 & 6 & 11 & 2 & 3 & 5 & 4 & 2 & 2 & 4 & 2 \\
\hline EML1322, EML1323 & 64 & 13 & 14 & 4 & 5 & 2.5 & 8 & 4 & 9 & 6 & 3 & 4 & 6 & 3 & 5 & 4 & 2 \\
\hline EML1326, EML1327 & 65 & 17 & 11 & 7 & 3 & 1.5 & 8 & 6 & 11 & 2 & 3 & 5 & 99 & 2 & 2 & 4 & 2 \\
\hline EML1328 & 66 & 17 & 11 & 7 & 3 & 1.5 & 8 & 6 & 11 & 2 & 3 & 5 & 2 & 2 & 2 & 4 & 2 \\
\hline EML1329 & 67 & 17 & 11 & 7 & 3 & 1.5 & 8 & 6 & 11 & 2 & 3 & 5 & 3 & 2 & 2 & 4 & 2 \\
\hline EML1331 & 68 & & 11 & 13 & 9 & 5 & 9 & 1 & 10 & 3 & 6 & 3 & 2 & 2 & 6 & 5.5 & 3 \\
\hline EML1332 & 69 & & 11 & 9 & 3 & 2.5 & 9 & 2 & 8.5 & 2 & 5 & 6 & 2.5 & 3 & 1 & 5 & 2 \\
\hline EML1333 & 70 & & 10 & 9 & 4 & 2.5 & 9 & 4 & 12 & 6 & 1 & 3 & 6 & 2 & 4 & 4 & 4 \\
\hline EML1334 & 71 & 10 & 11 & 7 & 3 & 2.5 & 9 & 2 & 99 & 3 & 4 & 3 & 2.5 & 1 & 1 & 2 & 2 \\
\hline EML1335 & 72 & 11 & 8 & 11 & 3 & 2.5 & 8 & 4 & 10 & 7 & 5 & 3 & 4 & 2 & 1 & 2 & 2 \\
\hline EML1336 & 73 & 11 & 7 & 11 & 3 & 2.5 & 8 & 4 & 10 & 7 & 5 & 3 & 4 & 2 & 1 & 2 & 2 \\
\hline
\end{tabular}

Based on the observations mentioned above, ms172 data and ms127 data were removed from clustering analysis. A new MLVA scheme called MLVA 13 -Lyon, showing high discriminatory power and typability of $90 \%$ was then defined (Table 4). MLVA typing of the 105 isolates using the MLVA $_{13^{-}}$ Lyon scheme led to differentiating 73 MTs (Table 3). These isolates were clustered into $17 \mathrm{MCs}$. As a comparison, the $\mathrm{MLVA}_{9}$-London and $\mathrm{MLVA}_{9}$-Utrecht schemes segregated the isolates into 70 MTs and 62 MTs, respectively.

The typability and HGDIs of the three MLVA schemes were compared (Table 4). The lower typability of the MLVA $_{9-}$ London scheme was partly due to the numerous absences of amplification observed with ms172. The HGDIs of the different MLVA schemes were superior to 0.982 (Table 4), while the MLVA $_{9}$-Utrecht scheme had significantly lower discriminatory power $(p=0.028)$.

The three typing schemes were highly congruent at the MT level, with the lowest adjusted Rand coefficients of 0.772 and 0.833 for $\mathrm{MLVA}_{9}$-Utrecht vs $\mathrm{MLVA}_{9}$-London, and $\mathrm{MLVA}_{13^{-}}$ Lyon respectively. The adjusted Rand coefficient between $\mathrm{MLVA}_{9}$-London and $\mathrm{MLVA}_{13}$-Lyon was 0.916. In addition, two isolates with the same MT in one of the MLVA schemes had a high probability of being classified in the same MT with another of the two MLVA schemes, as indicated by the adjusted Wallace coefficient (Table 5).

Representative snake isolates from feces and breeding facilities previously characterized using PFGE [5] were selected to validate the typing achieved by the MLVA $_{13}$-Lyon scheme on a restricted number of isolates of known diversity. Results showed that this scheme enabled discrimination of isolates in a manner similar to that obtained by PFGE (Fig. 2). In some instances, the $\mathrm{MLVA}_{13}$-Lyon scheme showed more discriminatory power than PFGE, as isolates belonging to the same PFGE type clustered in different MTs. For example, isolates EML64, EML100 and EML109 of the MC16 clustered into two distinct MTs differing at ms61 and ms213 markers (MT19 and MT29), while they were grouped into a single PFGE type (clone PFGE IX). Likewise, MLVA typing of isolates EML91, EML138 and EML145 belonging to PFGE CC I composed of two PFGE types segregated them into three MTs clustered in MC7 (MT25, MT30 and MT31 respectively), with EML91 and EML145 showing different genotypes of one repeat unit at the ms61 marker.

Given these results, the MLVA $_{13}$-Lyon scheme seemed to be consistent with PFGE typing, unlike the $\mathrm{MLVA}_{9}$-Utrecht scheme that showed a weaker discriminatory power and did

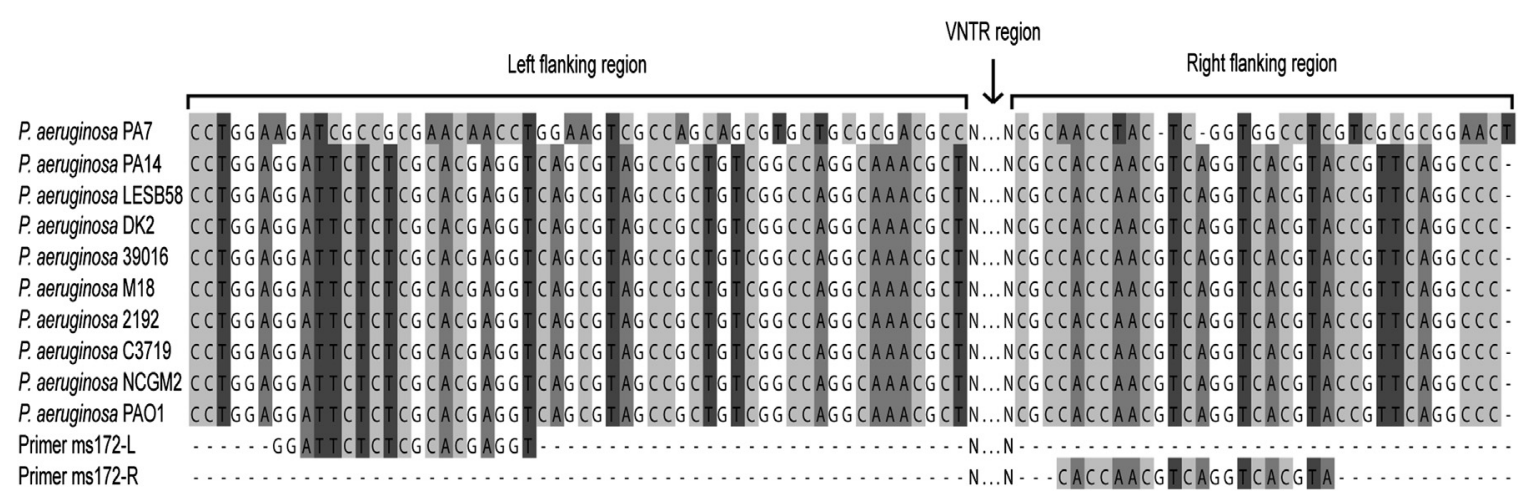

Fig. 1. Alignment of the genomic DNA sequences of type strains of $P$. aeruginosa bordering the ms 172 marker, and primers used for amplification. 
not segregate isolates according to PFGE. In contrast, the MLVA $_{9}$-London scheme that showed high discriminatory power with a threshold of one difference between two distinct MCs led to segregation of isolates belonging to PFGE CC I and clone IX in different MCs (data not shown).

\subsection{Diversity of soil and manure isolates}

The 62 isolates from soil $(n=23)$ and manure $(n=39)$ typed using the MLVA $_{13}$-Lyon scheme were resolved into 41 MTs, with 26 MTs clustered into $10 \mathrm{MCs}$ (Fig. 2). High diversity was observed with an HGDI of 0.971 and 16 isolates (61.5\%) showing a single MT.

Twelve out of 23 soil isolates showed seven MTs and clustered into three MCs (MC9, MC13 and MC17). Eleven isolates showed a single MT and did not cluster with any of the defined MCs. P. aeruginosa MT diversity was observed both within and between samples. For instance the eight isolates originating from soil sampled at Ouagadougou, Burkina Faso, had a different MT, and none grouped within an MC. Similarly, the three isolates from hydrocarbon-impacted soil in Paris showed three single MTs. Finally, three MTs clustered into two MCs (MC9 and MC13) were observed among the nine isolates from Neuves-Maison, and two MTs clustered into one MC (MC17) were observed among the isolates from Chinon soil. It should be noted that MTs and MCs identified among the soil isolates never clustered with isolates of different geographic origins.

Among manure isolates, 34 out of 39 isolates were resolved into 20 MTs clustered into eight MCs. Five isolates showed a unique MT and did not cluster within MC. MT diversity was also observed between and within manure samples. For instance, the five isolates from cattle manure from Versailleux clustered into two MCs (MC6 and MC14) of two isolates and one isolate (EML1268) with a unique MT. Similarly, isolates of horse manure from St Olive showed three MTs, with two being clustered in the same MC (MC12). However, we were able to cluster isolates from different animal manures and from different farms into the same MC. For instance, MC3 (consisting of a single MT, MT49) clustered one isolate from cattle manure sampled in Feucherolles with seven isolates of composted horse manure from two farms in Versailles. Similarly, MC10 included isolates from the same animal manure i.e. that of horses, but of different origin: indeed, eight isolates were from manure sampled at Versailles and one isolate was from manure sampled at Marcy l'Etoile, yet these isolates showed seven different MTs.

The MLVA also showed that isolates from different regions and different types of samples (soil or manure) could belong to

Table 4

Typability and Hunter-Gaston discriminatory Index (HGDI) with 95\% confidence Interval of each compared MLVA scheme.

\begin{tabular}{llll}
\hline MLVA scheme & Typability (\%) & HGDI index & Confidence interval \\
\hline MLVA $_{13}$-Lyon & 90 & 0.987 & $0.979-0.995$ \\
MLVA $_{9}$-London & 70 & 0.984 & $0.976-0.993$ \\
MLVA $_{9}$-Utrecht & 93 & 0.982 & $0.974-0.993$ \\
\hline
\end{tabular}

Table 5

Adjusted Wallace coefficient indicating congruence between the different MLVA schemes.

\begin{tabular}{llll}
\hline & MLVA $_{13}$-Lyon & MLVA $_{9}$-London & MLVA $_{9}$-Utrecht \\
\hline MLVA $_{13}$-Lyon & & 1 & 0.986 \\
& & $(1.000-1.000)$ & $(0.972-1.000)$ \\
MLVA $_{9}$-London & 0.847 & & 0.835 \\
& $(0.801-0.893)$ & & $(0.788-0.882)$ \\
MLVA $_{9}$-Utrecht & 0.724 & 0.724 & \\
& $(0.652-0.797)$ & $(0.652-0.797)$ & \\
\hline
\end{tabular}

Numbers in brackets are $95 \%$ confidence intervals.

the same MC. MC17 comprised three horse manure isolates from Marcy l'Etoile and three isolates from a vineyard soil amended with mushroom manure in Chinon.

No isolates from soil and manure clustered with strains from international collections whatever their origin, nor with snake-related isolates. None of the MTs obtained for the 62 isolates from soil and manure and the 17 isolates from the international collection matched with well-known lineage from a database of 454 clinical isolates of $P$. aeruginosa MLVA types previously described [24,39,46,48] and publicly available at http://mlva.u-psud.fr/mlvav4/genotyping/index. php (data not shown). However, isolates EML91, EML138 and EML145 from snakes belonging to MC16 showed MTs having only two alleles different from an MLVA clonal complex that includes isolates from urine, pus and pleural exudate studied in [24]. Thus, the present work led to highlighting new MTs as well as new MCs that only include environmental isolates.

\subsection{Antimicrobial resistance among soil and manure isolates of $P$. aeruginosa}

Antimicrobial resistance of $P$. aeruginosa isolates was tested. Like the wild-type, all soil and manure isolates (100\%) were resistant to minocycline and trimethoprim/sulfamethoxazole and sensitive to colistin, ciprofloxacin, isepamicin, amikacin, meropenem, aztreonam, cefepim and ceftazidim (data not shown). Resistance to ticarcillin and ticarcillin/claculanic acid was sporadically observed among isolates from manure: an isolate from cattle manure sampled at Feucherolles (EML1280) with a single MT and an isolate from horse manure sampled at St Olive (EML1274). The latter, belonging to $\mathrm{MC12}$, showed this resistance profile, while all other isolates belonging to this $\mathrm{MC}$ had a wild-type phenotype. It is noteworthy that EML1274 differed from other isolates of MC12 in the number of copies at the ms61 marker. This resistance to ticarcillin and ticarcillin/clavulanic acid was also observed among soil isolates: EML1321 (MC49) and EML1322 (MC13) isolates from hydrocarbon-impacted soil in Lorraine, with the latter also being resistant to imipenem $(\mathrm{MIC} \geq 16 \mathrm{mg} / \mu \mathrm{l})$. Others isolates included in these two MCs did not show an extended spectrum of antibiotic resistance. Resistance to ticarcillin and ticarcillin/clavulanic acid was also encountered in strains from international collections isolated from rhizospheres (7NSK2), hydrocarbon-contaminated soils 


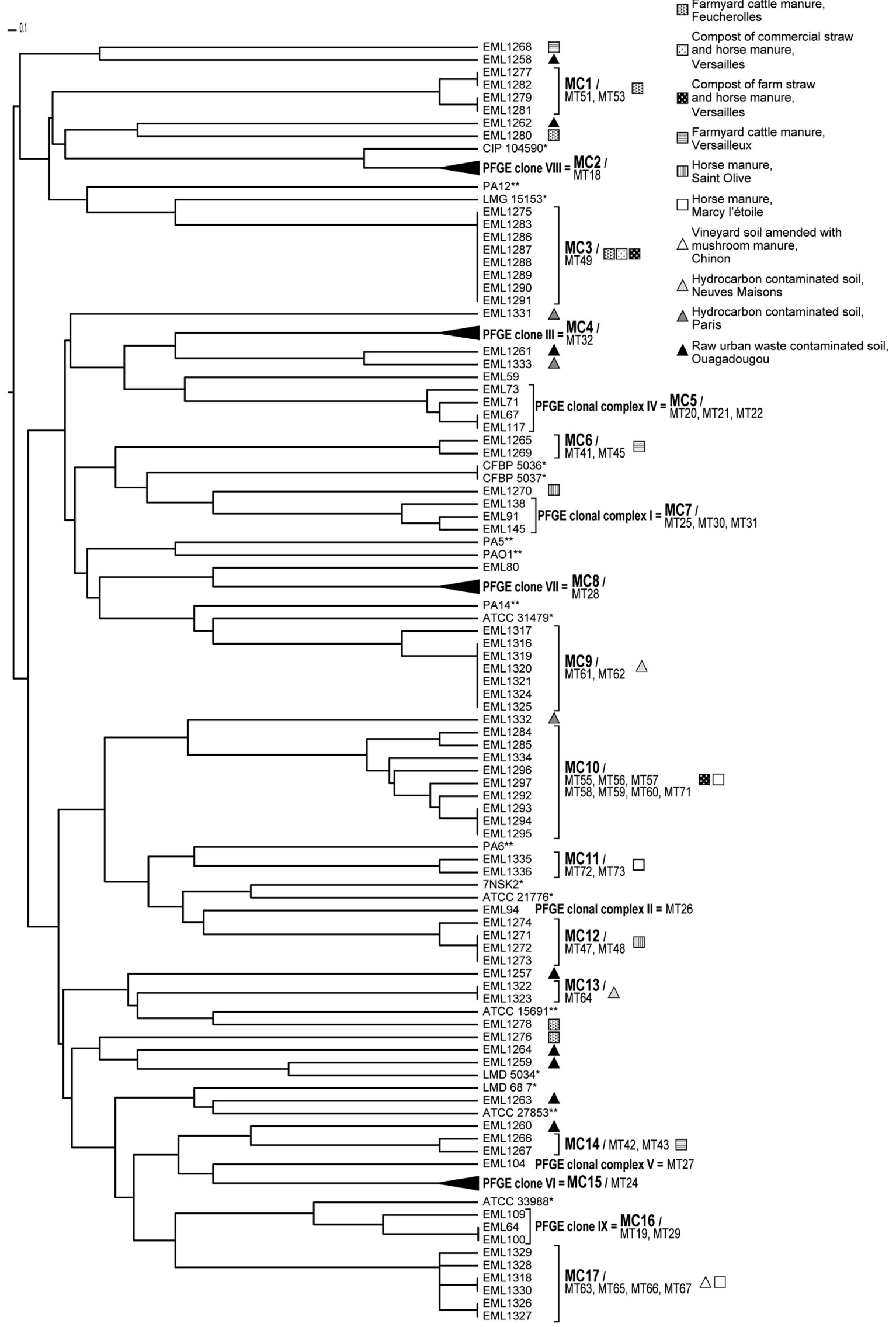


(CIP104590) and bulk soil (LMD5034, which was also resistant to pefloxacin, but not to ticarcillin alone). As a reminder, isolates EML88, EML138 and EML145 (PFGE clone VI) isolated from snake feces in the study of [5] were resistant to gentamicin and tobramycin, but this phenotype was not observed in isolates from soil and manure. Only strain PA6 of clinical origin from an international collection showed a resistance phenotype with additional resistance to ticarcillin, ticarcillin/clavulanic acid, piperacillin and piperacillin/tazobactam. No other isolate besides EML1322 showed resistance to imipenem.

\section{Discussion}

The extent of diversity of environmental $P$. aeruginosa isolates from non-aquatic environments and their similarity with clinical ones has been poorly investigated, partly due to the low number of available isolates from non-aquatic origin in international collections. We sought to fill this gap by investigating the genetic diversity of 62 isolates from soil and manure using the MLVA typing method.

In order to optimize the method, we sought to develop an MLVA scheme based on a low number of markers and enabling good typability and high discriminatory power. As no data on the diversity and typing ability of environmental isolates were available, 15 markers previously used in the 9marker MLVA schemes developed by [45] and [46] were selected. Among the 15 markers, two of them did not fulfil the criteria of typability and discriminatory power. The ms 172 marker, which often led to non-amplification, and the ms 127 marker, which provided little discrimination, were thus removed from the analysis. Despite the congruence between the MLVA13-Lyon scheme and the two simplified MLVA9Utrecht and MLVA9-London schemes, typability and discriminatory indexes as well as comparison to the clustering of snake isolates with PFGE revealed that our scheme was the most efficient for the typing and clustering of environmental isolates. As suggested by [39], the typing of a larger number of VNTRs increases the probability of subtyping some clones. Thus, the MLVA $_{13}$-Lyon scheme might be accurate in epidemiological studies and analysis of the population structure of large sets of clinical and environmental $P$. aeruginosa isolates.

As previously reported for epidemiological studies [46], strong diversity reflected by the identification of 41 MTs was observed among our 62 soil and manure isolates. Such diversity has also been observed in studies on aquatic, animal and other non-clinical isolates [32,33]. Ten MLVA clusters were clearly identified. Most of these clusters were composed of isolates of the same geographic origin and from the same source of sample (i.e. soil or manure), with a few exceptions (MC3, MC10 and MC17). These findings are similar to those of a recent study by [43] that compared cattle, aquatic and clinical strains of $P$. aeruginosa and observed that genotypes of cattle strains differed from those of human clinical strains. However, our results contrasted with those obtained by [33], who observed no clear correlation between the clonal complexes and geographic origin or habitat. Unlike studies on $P$. aeruginosa population structure [50], genotypic divergence was observed between isolates from soil and manure and isolates from an international collection and from snake feces and breeding facilities. Furthermore, comparison of soil and manure MTs with the $P$. aeruginosa MLVA database showed that none of the MTs from soil or manure corresponded to already defined lineages. Such divergence was also observed by [43] with regard to the clonality of cattle and human strains. It is noteworthy that isolates from snakes belonging to MC16 showed MTs with only 2 different alleles, with an MLVA clonal complex that includes isolates from urine, pus and pleural exudate studied in [24]. However the absence of relationships between our terrestrial genotypes and clinical ones could be due to our sampling strategy, since a limited number of different geographic origins as well as a low number of isolates, especially from soil, were tested. As discussed in [23], this might have biased our evaluation of the diversity of $P$. aeruginosa within each habitat, i.e. soil and manure, and consequently, the potential correlation between clones or clonal complexes and habitat.

No common MTs were found among the soil isolates having different geographic origins. Although the sample size was limited, because of the low abundance of $P$. aeruginosa populations in terrestrial environments [1,6,12], it was observed that soil isolates exhibited differing levels of diversity according to their geographic origin. For instance, each of the 8 isolates from Ouagadougou showed a unique MT. Conversely, low diversity was observed within the soil contaminated with hydrocarbons sampled at Neuves-Maison where the 9 isolates clustered within 2 MCs. These differences in isolate diversity could be related to the differing severity of selective pressure of hydrocarbon and raw urban waste $[30,42]$. However, 3 MTs were observed among the 4 isolates obtained from the hydrocarbon-contaminated soil collected in Paris. It would thus be interesting to analyze larger sets of isolates from a more diverse soil type set under various anthropic constraints and geographic origins to obtain a more accurate measurement of the selection impact of human activities on the diversity and structure of the soil population of P. aeruginosa.

Isolates from manure also exhibited diversity between and within samples. Nevertheless, some isolates of differing geographic and animal origin were clustered. The clustering of isolates from the same host, i.e. the horse, but from different farms located in different regions of France, like those in the MC10, suggests the existence of widespread clones adapted to a host. The spread of major cattle clones in different

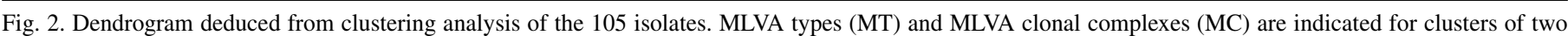

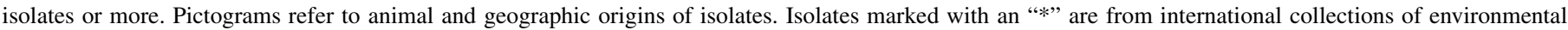

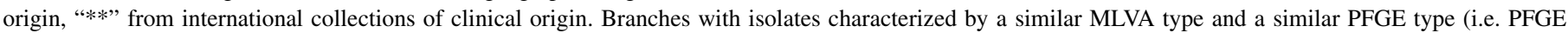
clone) were collapsed. 
Hungarian regions was also reported by [43]. However, isolates from horse and cattle manure sampled at 3 farms located close to one another in the Ile-de-France were clustered into MC3. This observation undermines the hypothesis of hostadapted strains and suggests, like other studies, that there is no correlation between the $P$. aeruginos a clone and the habitat such as the host [31,36]. As these isolates originated from neighboring farms, the spread of a clone in different hosts could occur over a restricted area. The clustering of horse manure isolates and mushroom manure amended soil isolates in MC17 support the notion of environmental and host adaptability. But since French mushroom manure used for field amendment is partly composed of horse manure, all these isolates might have an animal origin. [43] highlighted the possibility of natural exchange between environmental and animal strains. Therefore, the survival of $P$. aeruginosa after amendment should be assessed to elucidate the origin of the isolates from amended soils.

Antibiotic resistance profiles were performed to determine a potential link between resistance properties and the selective pressure that might be exerted in the various habitats. Almost all isolates from soil and manure showed wild-type antibiotic resistance profiles. Two isolates from hydrocarbon-impacted soils from Neuves-Maisons were found to be resistant to ticarcillin, coupled or not with clavulanic acid. One of them was also resistant to imipenem. In their study, [19] found resistance to at least 2 antibiotic classes, including extended spectrum penicillins and carbapenem, in $33 \%$ of isolates from hydrocarbon-contaminated sites. This suggested that hydrocarbon contamination could lead to a selection of resistant phenotypes. No resistance was observed among isolates from Burkina Faso soils. As antibiotic use for human or animal medicine is low in that country, the presence of antibiotics in such amended soils, and consequently, antibiotic selective pressure, is unlikely. However, as $\mathrm{Zn}, \mathrm{Pb}$ and $\mathrm{Hg}$ contamination was reported in these soils (Hien, personal communication) metal contamination could act as a selective pressure that might co-select antibiotic resistance and metal resistance [2].

Considering manure isolates, only 2 out of 39 isolates displayed resistance to ticarcillin and ticarcillin/clavulanic acid. These results contrasted with a previous work wherein antibiotic resistance was detected among isolates from manure containing compost, especially against carbapenem and thirdgeneration cephalosporin [20]. This low resistance could be explained by low selective pressure, i.e. low amounts of antibiotics in manure and low exposure in animals. Detailed information on the different types and intensity of antimicrobial selective pressure exerted on our isolate collection could not be obtained. However, in these livestock farms that are not intensive, antibiotics are not delivered at sub-therapeutic levels and are used only occasionally to treat infections (mainly oxytetracycline in bovine farms). Consequently antibiotics might have been present rarely, both in animals and manure, and/or at a low level and for a short period of time. Details on the eventual doses and frequencies of antibiotic administration to the animals and measurement of antibiotic amounts in manure would thus be needed to reach a conclusion concerning the exact role of antibiotic treatment and environmental dispersion on resistance selection. One of the manure-resistant isolates was clustered with others that displayed a wild-type phenotype, suggesting that the genetic content and organization of a strain is not correlated with its resistance phenotype [21].

In summary, this study demonstrates that the MLVA method is suitable for the typing of $P$. aeruginosa isolates from terrestrial environments. It can be concluded that the population structure of $P$. aeruginosa from manure and soil was highly diverse, with strains diverging from those in international strain collections of environmental and clinical origin. Whether a correlation between genotype and habitat exists could not be inferred based on our data due to the insufficient richness of our set of isolates. No significant antibiotic resistance was observed among these isolates, suggesting that environmental conditions encountered in soil and manure did not favor antibiotic resistance selection. Further studies on a set of unrelated and more diverse isolates are thus needed: i) to elucidate relationships between strains capable of colonizing animals and soil, and the broader set of $P$. aeruginosa isolates found in aquatic environments and in hospitals; and ii) to evaluate the distribution of terrestrial genotypes and their ability to colonize various niches and evolve towards resistant epidemic clones.

\section{Acknowledgements}

We thank the DTAMB platform for technical assistance and Jean Thioulouse (UMR CNRS 5558 Biométrie et Biologie evolutive, Lyon) for his help in statistical analyses. This work was funded by the 'Agence Nationale de la Recherche' (ANR) (program 07 SEST project 018-01) and the CNRS (Centre national de la Recherche scientifique). B. Youenou was funded by a grant from the French Environment and Energy Management Agency (ADEME) and the French "Direction générale de l'Armement" (DGA).

\section{References}

[1] Aoi Y, Nakata H, Kida H. Isolation of Pseudomonas aeruginosa from Ushubetsu River water in Hokkaido, Japan. Jpn J Vet Res 2000;48:29-34.

[2] Baker-Austin C, Wright M, Stepanauskas R, McArthur J. Co-selection of antibiotic and metal resistance. Trends Microbiol 2006;14:176-82.

[3] Barben J, Hafen G, Schmid J, Swiss Paediatric Respiratory Research, G. Pseudomonas aeruginosa in public swimming pools and bathroom water of patients with cystic fibrosis. J Cyst Fibros 2005;4:227-31.

[4] Carrico JA, Silva-Costa C, Melo-Cristino J, Pinto FR, de Lencastre H, Almeida JS, et al. Illustration of a common framework for relating multiple typing methods by application to macrolide-resistant Streptococcus pyogenes. J Clin Microbiol 2006;44:2524-32.

[5] Colinon C, Jocktane D, Brothier E, Rossolini G, Cournoyer B, Nazaret S. Genetic analyses of Pseudomonas aeruginosa isolated from healthy captive snakes: evidence of high inter- and intrasite dissemination and occurrence of antibiotic resistance genes. Environ Microbiol 2010;12:716-29.

[6] Colinon C, Deredjian A, Hien E, Brothier E, Bouziri L, Cournoyer B, et al. Detection and enumeration of Pseudomonas aeruginosa in soil and manure assessed by an ecfX qPCR assay. J Appl Microbiol 2013;114:1734-49. 
[7] Cramer N, Wiehlmann L, Tümmler B. Clonal epidemiology of Pseudomonas aeruginosa in cystic fibrosis. Int J Med Microbiol 2010;300:526-33.

[8] Daly M, Power E, Björkroth J, Sheehan P, O’Connell A, Colgan M, et al. Molecular analysis of Pseudomonas aeruginosa: epidemiological investigation of mastitis outbreaks in Irish dairy herds. Appl Environ Microbiol 1999;65:2723-9.

[9] Deredjian A, Colinon C, Brothier E, Favre-Bonté S, Cournoyer B, Nazaret S. Antibiotic and metal resistance among hospital and outdoor strains of Pseudomonas aeruginosa. Res Microbiol 2011;162:689-700.

[10] Deziel E, Paquette G, Villemur R, Lepine F, Bisaillon J. Biosurfactant production by a soil Pseudomonas strain growing on polycyclic aromatic hydrocarbons. Appl Environ Microbiol 1996;62:1908-12.

[11] Filali BK, Taoufik J, Zeroual Y, Dzairi FZ, Talbi M, Blaghen M. Waste water bacterial isolates resistant to heavy metals and antibiotics. Curr Microbiol 2000;41:151-6.

[12] Green S, Schroth M, Cho J, Kominos S, Vitanza-jack V. Agricultural plants and soil as a reservoir for Pseudomonas aeruginosa. Appl Microbiol 1974;28:987-91.

[13] Grundmann H, Schneider C, Hartung D, Daschner F, Pitt T. Discriminatory power of three DNA-based typing techniques for Pseudomonas aeruginosa. J Clin Microbiol 1995;33:528-34.

[14] Grundmann H, Hori S, Tanner G. Determining confidence intervals when measuring genetic diversity and the discriminatory abilities of typing methods for microorganisms. J Clin Microbiol 2001;39:4190-2.

[15] Heslop A, Ovesen T. Severe acute middle ear infections: microbiology and treatment. Int J Pediatr Otorhinolaryngol 2006;70:1811-6.

[16] Hunter PR, Gaston MA. Numerical index of the discriminatory ability of typing systems: an application of Simpson's index of diversity. J Clin Microbiol 1988;26:2465-6.

[17] Hunter PR. The microbiology of bottled natural mineral waters. J Appl Bacteriol 1993;74:345-52.

[18] Johnson J, Arduino S, Stine O, Johnson J, Harris A. Multilocus sequence typing compared to pulsed-field gel electrophoresis for molecular typing of Pseudomonas aeruginosa. J Clin Microbiol 2007;45:3707-12.

[19] Kaszab E, Kriszt B, Atzél B, Szabó G, Szabó I, Harkai P, et al. The occurrence of multidrug-resistant Pseudomonas aeruginosa on hydrocarbon-contaminated sites. Microb Ecol 2010;59:37-45.

[20] Kaszab E, Szoboszlay S, Dobolyi C, Háhn J, Pék N, Kriszt B. Antibiotic resistance profiles and virulence markers of Pseudomonas aeruginosa strains isolated from composts. Bioresour Technol 2011;102:1543-8.

[21] Khan N, Ishii Y, Kimata-Kino N, Esaki H, Nishino T, Nishimura M, et al. Isolation of Pseudomonas aeruginosa from open ocean and comparison with freshwater, clinical, and animal isolates. Microb Ecol 2007;53:173-86.

[22] Kimata N, Nishino T, Suzuki S, Kogure K. Pseudomonas aeruginosa isolated from marine environments in Tokyo Bay. Microb Ecol 2004;47:41-7.

[23] Lanotte P, Watt S, Mereghetti L, Dartiguelongue N, Rastegar-Lari A, Goudeau A, et al. Genetic features of Pseudomonas aeruginosa isolates from cystic fibrosis patients compared with those of isolates from other origins. J Med Microbiol 2004;53:73-81.

[24] Larché J, Pouillot F, Essoh C, Libisch B, Straut M, Lee J, et al. Rapid identification of international multidrug-resistant Pseudomonas aeruginosa clones by multiple-locus variable number of tandem repeats analysis and investigation of their susceptibility to lytic bacteriophages. Antimicrob Agents Chemother 2012;56:6175-80.

[25] Ledbetter E, Hendricks L, Riis R, Scarlett J. In vitro fluoroquinolone susceptibility of Pseudomonas aeruginosa isolates from dogs with ulcerative keratitis. Am J Vet Res 2007;68:638-42.

[26] Libisch B, Watine J, Balogh B, Gacs M, Muzslay M, Szabó G, et al. Molecular typing indicates an important role for two international clonal complexes in dissemination of VIM-producing Pseudomonas aeruginosa clinical isolates in Hungary. Res Microbiol 2008;159:162-8.

[27] LiPuma JJ. The changing microbial epidemiology in cystic fibrosis. Clin Microbiol Rev 2010;23:299-323.

[28] Maslow JN, Mulligan ME, Arbeit RD. Molecular epidemiology application of contemporary techniques to the typing of micoorganisms. Clin Infect Dis 1993;17:153-64.
[29] Onteniente L, Brisse S, Tassios PT, Vergnaud G. Evaluation of the Polymorphisms associated with tandem repeats for Pseudomonas aeruginosa strain typing. J Clin Microbiol 2003;41:4991-7.

[30] Pérez-Leblic M, Turmero A, Hernández M, Hernández A, Pastor J, Ball A, et al. Influence of xenobiotic contaminants on landfill soil microbial activity and diversity. J Environ Manage 2012;95(Suppl.):90.

[31] Pirnay J-P, De Vos D, Cochez C, Bilocq F, Vanderkelen A, Zizi M, et al. Pseudomonas aeruginosa displays an epidemic population structure. Environ Microbiol 2002;4:898-911.

[32] Pirnay J-P, Matthijs S, Colak H, Chablain P, Bilocq F, Van Eldere J, et al. Global Pseudomonas aeruginosa biodiversity as reflected in a Belgian river. Environ Microbiol 2005;7:969-80.

[33] Pirnay J-P, Bilocq F, Pot B, Cornelis P, Zizi M, Van Eldere J, et al. Pseudomonas aeruginosa population structure revisited. PLoS ONE 2009;4.

[34] Pitcher DG, Saunders NA, Owen RJ. Rapid extraction of bacterial genomic DNA with guanidium thiocyanate. Lett Appl Microbiol 1989;8:151-6.

[35] Rand WM. Objective criteria for the evaluation of clustering methods. J Am Stat Assoc 1971;66:846-50.

[36] Römling U, Wingender J, Muller H, Tummler B. A major Pseudomonas aeruginosa clone common to patients and aquatic habitats. Appl Environ Microbiol 1994;60:1734-8.

[37] Selezska K, Kazmierczak M, Müsken M, Garbe J, Schobert M, Häussler S, et al. Pseudomonas aeruginosa population structure revisited under environmental focus: impact of water quality and phage pressure. Environ Microbiol 2012;14:1952-67.

[38] Simpson EH. Measurement of diversity. Nature 1949;163:688.

[39] Sobral D, Mariani-Kurkdjian P, Bingen E, Vu-Thien H, Hormigos K, Lebeau B, et al. A new highly discriminatory multiplex capillary-based MLVA assay as a tool for the epidemiological survey of Pseudomonas aeruginosa in cystic fibrosis patients. Eur $\mathrm{J}$ Clin Microbiol 2012;31:2247-56.

[40] Sokal RR, Michener CD. A statistical method for evaluating systematic relationships. Univ Kans Sci Bull 1958;28:1409-38.

[41] Song K, Chan T, Ji Z, Wong S. Rapid identification of Pseudomonas aeruginosa from ocular isolates by PCR using exotoxin A-specific primers. Mol Cell Probes 2000;14:199-204.

[42] Sutton N, Maphosa F, Morillo J, Abu Al-Soud W, Langenhoff A, Grotenhuis $\mathrm{T}$, et al. Impact of long-term diesel contamination on soil microbial community structure. Appl Environ Microbiol 2013;79:619-30.

[43] Szmolka A, Cramer N, Nagy B. Comparative genomic analysis of bovine, environmental, and human strains of Pseudomonas aeruginosa. FEMS Microbiol Lett 2012;335:113-22.

[44] Tate D, Mawer S, Newton A. Outbreak of Pseudomonas aeruginosa folliculitis associated with a swimming pool inflatable. Epidemiol Infect 2003;130:187-92.

[45] Turton JF, Turton SE, Yearwood L, Yarde S, Kaufmann ME, Pitt TL. Evaluation of a nine-locus variable-number tandem-repeat scheme for typing of Pseudomonas aeruginosa. Clin Microbiol Infect 2010;16:1111-6.

[46] van Mansfeld R, Jongerden I, Bootsma M, Buiting A, Bonten M, Willems R. The population genetics of Pseudomonas aeruginosa isolates from different patient populations Exhibits high-level host Specificity. PLoS ONE 2010;5:e13482.

[47] Vergnaud G, Pourcel C. Multiple locus variable number of tandem repeats analysis. Methods Mol Biol. 2009;551:141-58.

[48] Vu-Thien H, Corbineau G, Hormigos K, Fauroux B, Corvol H, Clement A, et al. Multiple-Locus Variable-Number Tandem-Repeat Analysis for longitudinal survey of sources of Pseudomonas aeruginosa infection in cystic fibrosis patients. J Clin Microbiol 2007;45:3175-83.

[49] Wallace DL. A method for comparing two hierarchical clusterings: comment. J Am Stat Assoc 1983;78:569-76.

[50] Wiehlmann L, Wagner G, Cramer N, Siebert B, Gudowius P, Morales G, et al. Population structure of Pseudomonas aeruginosa. Proc Natl Acad Sci U S A 2007;104:8101-6. 